\title{
Factor structure of suggestibility revisited: new evidence for direct and indirect suggestibility
}

\author{
Romuald Polczyk \\ Institute of Psychology, Jagiellonian University, Krakow, Poland
}

\section{BACKGROUND}

Yielding to suggestions can be viewed as a relatively stable individual trait, called suggestibility. It has been long proposed that there are two kinds of suggestible influence, and two kinds of suggestibility corresponding to them: direct and indirect. Direct suggestion involves overt unhidden influence, while indirect suggestion concerns influence that is hidden, and the participant does not know that the suggestibility is being measured. So far however, empirical evidence for the existence of the two factors has been scarce. In the present study, more sophisticated and reliable tools for measuring suggestibility were applied than in the previous research, in the hope that better measurement would reveal the factor structure of suggestibility. Two tests of direct suggestibility were used: the Harvard Group Scale of Hypnotic Susceptibility, Form A, measuring hypnotic susceptibility, and the Barber Suggestibility Scale, measuring non-hypnotic direct imaginative suggestibility. Three tests served to measure indirect suggestibility: the Sensory Suggestibility Scale, measuring indirect suggestibility relating to perception; the Gudjonsson Suggestibility Scale, measuring the tendency to yield to suggestive questions and changing answers after negative feedback; and the Emotional Dialogs Tests, measuring the tendency to perceive nonexistent aggression.

PARTICIPANTS AND PROCEDURE

In sum, 115 participants were tested, 69 women, 49 men, mean age 22.20 years, $S D=2.20$. Participants were tested in two sessions, lasting for a total of four hours.

\section{RESULTS}

Confirmatory factor analyses confirmed the existence of two uncorrelated factors of suggestibility: direct and indirect.

\section{CONCLUSIONS}

Suggestibility may indeed involve two factors, direct and indirect, and failure to discover them in previous research may be due to methodological problems.

\section{KEY WORDS}

confirmatory factor analysis; suggestion; suggestibility; direct suggestibility; indirect suggestibility

CORReSPONDING AUthor - Prof. Romuald Polczyk, Institute of Psychology, Jagiellonian University, 6 Ingardena Str., 30-060 Krakow, Poland, e-mail: romuald.polczyk@uj.edu.pl

Authors' COntribution - A: Study design · B: Data collection · C: Statistical analysis · D: Data interpretation .

E: Manuscript preparation · F: Literature search · G: Funds collection

TO CITE THIS ARTICLE - Polczyk, R. (2016). Factor structure of suggestibility revisited: new evidence for direct and

indirect suggestibility. Current Issues in Personality Psychology, 4(2), 87-96.

RECEIVED 10.12.2015 - REVIEWED 23.02.2016 · ACCEPTED 10.05.2016 · PUBLISHED 03.06.2016 


\section{BACKGROUND}

Research on suggestion and suggestibility is one of the oldest topics in scientific psychology. It was carried out very intensely already at the beginning of scientific psychology, and the most important psychologists of that time contributed to it, e.g. Binet (1900), Freud (1920/1975), James (1896), Wundt (1892) and McDougall (1908). Afterwards, this topic disappeared from psychology almost completely, probably due to behaviorism and psychoanalysis - both these approaches discarded the term suggestion, although for different reasons. In contemporary psychology, a resurgence of the issues connected with suggestion and suggestibility is apparent, mainly, but not exclusively, in the areas of forensic psychology (pioneering work: Loftus \& Palmer, 1974; Loftus, Miller, \& Burns, 1978; see also Gudjonsson, 1997), in research on hypnosis and hypnotizability (e.g. Green, Barabasz, Barrett, \& Montgomery, 2005; Lynn, Laurence, \& Kirsch, 2015), and in research on placebo effects (e.g. Darragh, Chang, Booth, \& Consedine, 2015). In this article, one of the oldest issues connected with research on suggestion is revisited, namely, the question of the factor structure of the individual trait called "suggestibility".

\section{SUGGESTION AND SUGGESTIBILITY}

In the literature, there exist many definitions of suggestion (for a review, see Gheorghiu, 1989). One of the most useful definitions is as follows: suggestion is "a process of communication during which one or more persons cause one or more individuals to change (without critical response) their judgments, opinions, attitudes, etc., or patterns of behaviour" (Eysenck, Arnold, \& Meilli, 1975, p. 1077). Thus, reacting to suggestions involves no rational thinking, which according to Gheorghiu (1989), is one of the crucial differences between suggestive and non-suggestive influence.

In the above-mentioned definition, the term "suggestion" refers to a process - a kind of influence. In contrast, the term "suggestibility" refers to an individual trait, connected with susceptibility to suggestions. Whether such an individual trait at all exists remains one of the most debated issues in research on suggestibility (comp. Eysenck, 1991). Research presented in this paper is connected with this topic.

\section{TYPES OF SUGGESTIBILITY}

Since the very beginning of research and thinking about suggestibility, it has been proposed that there are two kinds of it. Already in 1898 Sidis proposed that direct and indirect suggestive influence should be distinguished. Direct suggestions refer to the situation in which the influence is overt, not hidden, and the subject is perfectly aware that their susceptibility to some kind of influence is being measured. A good example of such direct influence may be the Body Sway Test, during which the subject is standing by a wall with his or her eyes closed, and the experimenter says repeatedly that the subject is falling backwards. Consistently, individual susceptibility to such overt suggestions is called direct suggestibility. In the Body Sway test, the direct suggestibility is measured as the amount of body sway caused by the suggestions.

In contrast, in the case of indirect suggestion the intention and purpose of exerting influence is hidden. An example may by the Heat Illusion Test: the subject is told that their sensitivity to warmth, or the ability to discover subtle changes in temperature, is going to be tested. The subject then puts his/her hand over a metal wire seemingly heated by an electric current, activated by a switch that is visible to the subject. The experimenter slowly turns on the controller, increasing the voltage. The metal wire indeed gets warmer, which is usually indicated by the subject. On the second trial, the current is turned off by means of a switch invisible to the subject. Reporting by the subject feelings of the nonexistent "warmth" is considered a symptom of indirect suggestibility, that is, susceptibility to hidden suggestive influence.

Perhaps because of lack of appropriate methodology allowing for empirical research on factor structure, this distinction remained largely a theoretical proposition until 1945, when Eysenck and Furneaux presented results of a factor analysis performed on a battery of 12 various suggestibility tests, the results of which they interpreted as two factors: primary suggestibility, and secondary suggestibility (that is, NOT as direct and indirect suggestibility). Primary suggestibility was defined as "the execution of a motor movement by the subject consequent upon the repeated suggestion by the experimenter that such a movement will take place, without conscious participation in the movement on the subject's part" (Eysenck, 1947, p. 165). Secondary suggestibility was "the experience on the part of the subject of a sensation or perception consequent upon indirect or implied suggestion by the experimenter that such an experience will take place in the absence of any objective basis for the sensation or perception" (Eysenck, 1947, p. 167). Eysenck and Furneaux also mentioned a "tertiary suggestibility", concerning susceptibility to prestige and authorities, but without empirical support.

Subsequent research of this kind usually confirmed that various measures of primary suggestibility as defined by Eysenck (1945) were intercorrelated, confirming the possible existence of this trait. In his review, Duke (1964) concluded that primary suggest- 
ibility tests correlated with hypnotizability as high as .60. More recently, Braffman and Kirsch (1999) found a substantial relationship between hypnotic and overt non-hypnotic susceptibility.

However, as for secondary suggestibility, research usually failed to confirm its existence as a clear unitary trait (Benton \& Bandura, 1953; Hammer, Evans, \& Bartlett, 1963; Stukat, 1958; Evans, 1967). Moreover, a reexamination of the factor analysis presented by Eysenck and Furneaux (1945), done by Evans (1967) by means of a reanalysis of the tetrachoric correlation matrix presented by them in their paper, failed to confirm the existence of the secondary suggestibility factor. Two more recent studies (Perez, Brown, Tasso, \& Nash, 2004; Perez, 2009) failed to confirm the three-factor structure (including tertiary/prestige suggestibility).

As for the independence of direct and indirect suggestibility, it seems that in most research results of tests of these two kinds were relatively uncorrelated. For example, Moore (1964) looked at the correlations between hypnotic susceptibility and three tests of susceptibility to hidden social influence: an influencibility test, measuring the degree to which individuals changed their opinions as a result of false peer group norm feedback data; a persuasibility test, assessing the proneness to changing personal opinions; and an autokinetic test, asking the participants to estimate movements of a light, which in reality did not move. The correlations between hypnotic susceptibility and the persuasibility test and autokinetic test were nonsignificant, and in the case of the influencibility test significant, but low. In addition, the correlations among the three indirect tests were nonsignificant.

In most experiments, hypnotic suggestibility proved to be unrelated to the magnitude of the placebo effect, which can be considered as a sort of indirect suggestibility (Evans, 1989; Baker \& Kirsch, 1993; Kirsch, 1997; McGlashen, Evans, \& Orne, 1969; Netter, Gheorghiu, Kruse, \& Hübner, 1989; Spanos, Perlini, \& Robertson, 1989; Spanos, Stenstrom, \& Johnston, 1988; Van Dyck \& Hoogduin, 1990). In contrast, Woody, Drugovic, and Oakman (1997) were able to find a significant relationship between hypnotic responding and nonhypnotic suggestibility related to placebo.

Direct influence in the form of hypnotizability seems also to be unrelated to a special kind of indirect suggestibility: interrogative suggestibility, which is defined as the proneness to yield to suggestive questions and to change answers after negative feedback (Gudjonsson, 1997; Gudjonsson \& Clark, 1986) (the scale measuring it was used in the present research and is described below). Usually, no relationship between hypnotizability and interrogative suggestibility has been found (e.g., Gwynn \& Spanos, 1996; Netter et al., 1989; Register \& Kihlstrom, 1988).
There are some exceptions to the rule that results of direct tests do not correlate with those from indirect ones. Linton and Sheehan (1994) were able to detect that hypnotizability was associated with elevated interrogative suggestibility. Hajek and Kratochvil (1973) and Hajek and Spacek (1987) were able to find a significant weak positive correlation between hypnotizability and indirect sensory suggestibility, as measured by the test of influencibility, in which the participants were told that a light was getting brighter (in reality it was not) and asked whether they could see it. Also, Polczyk and Pasek (2006) were able to demonstrate that the relationship between direct and hidden influence was positive and significant, provided that the area towards which the suggestions are directed is the same, namely bodily experiences. Also, Gheorghiu, Meiu, Onofrei, and Timofte (1966) and Gheorghiu (1971) were able to find significant positive correlations among various suggestibility tests administered in both direct and indirect form.

Taken together, existing results may be summarized as follows:

- various tests of primary suggestibility, in which overt suggestions concerning motoric bodily phenomena are involved, correlate positively and substantially, suggesting the existence of an individual trait;

- various tests of indirect suggestibility, including secondary suggestibility, do not exhibit substantial intercorrelations;

- tests of direct and indirect suggestibility usually do not correlate.

\section{BACKGROUND FOR THE PRESENT RESEARCH}

In order to further extend thinking and research on the factor structure of suggestibility, some clarification of the terms is needed first. As mentioned above, Eysenck (1947) defined primary suggestibility as overt influence towards motoric movements, and secondary suggestibility as a hidden influence aiming to change sensory perceptions. One problem connected with this classification is that it confounds explicit vs. hidden influence, and motoric vs. sensory phenomena (Gheorghiu, 1989). According to Gheorghiu, it is unclear why motoric phenomena could not be influenced in an indirect, hidden way, or why sensory sensations should be restricted to indirect suggestions. Gheorghiu (1989) presented a strong case that the most logical distinction of the kinds of suggestibility should be based on broad types of suggestive influence - direct and indirect - as already proposed by Sidis in 1898. Direct suggestibility would refer to reactions to overtly expressed and worded suggestions, no matter what the "content" of the suggestion is (whether motoric, sensory or other kind). In contrast, indirect suggestibility is connected 
with susceptibility to hidden suggestions, where the participant does not realize that their suggestibility is measured at all, again, no matter at which phenomena the suggestion is aimed.

The second problem with existing studies on the factor structure of suggestibility is that they involved mostly very simple tests of indirect suggestibility, most of them only allowing for a dichotomous classification: suggestible vs. non-suggestible (this is e.g. the case with the Heat Illusion Test, described above). It is possible that experiments using more sophisticated procedures, allowing for continuous measurement, and therefore for a gradation of individual suggestibility, would make it easier to discern the real factor structure. Thirdly, to my knowledge, no published study, apart from that of Perez et al. (2004), has used confirmatory factor analyses, most appropriate for testing hypotheses about structural models.

In this paper, I suggest that most problems present in the research on suggestibility may be connected with those simple, but influential, technical and methodological problems mentioned in the previous paragraph. Therefore, a study has been conducted in which only contemporary tests, constructed in accordance with the classical theory of testing, standardized, and of known reliability, were applied. Tests of indirect suggestibility were not restricted to the area of sensory sensations. The ambiguous terminology "primary" and "secondary" suggestibility was dropped; instead the terms "direct" and "indirect" suggestibility were used. The factor of "tertiary/prestige" suggestibility was not included in the analyses. Two hypotheses were verified:

1. There are two factors of suggestibility: direct and indirect, the first one referring to susceptibility to overt suggestions, the second to hidden ones;

2. Those two factors are independent, that is, uncorrelated.

Confirmatory factor analyses were used to analyze the results. Technically, the above hypotheses may be restated as follows: the tests HGSHS:A and BSS would load to one factor; the tests SSS, GSS, and EDT would load to the second factor; and both factors would be uncorrelated.

\section{PARTICIPANTS AND PROCEDURE}

\section{PARTICIPANTS}

One-hundred and fifty-two subjects initially participated in the experiment, but due to the missing second session or device failures 119 participants were available for analyzes, and one participant was dropped due to being an outlier on one of the tests (SSS, see description below). The sample available for analyses was therefore 118 (69 women and 49 men), with mean age 22.20 years $(S D=2.00$, range $18-29)$.
The participants received a small amount of money for their participation (20 PLN - about €5).

\section{MEASURES}

Tests of direct suggestibility:

Harvard Group Scale of Hypnotic Susceptibility, Form A (HGSHS:A; Shor \& Orne, 1962; Polish adaptation: Siuta, 1978). This tool was designed to measure hypnotic susceptibility. The procedure includes induction of hypnosis, by means of eye tiring, relaxation and monotonous counting, and afterwards, twelve test-suggestions are given: Postural Sway (given during the induction of hypnosis), Eye Closure, Hand Lowering, Hand Immobilization, Finger Lock, Arm Rigidity, Hands Moving Together, Verbal Inhibition (inability to say one's name), Hallucination of a fly, Eye catalepsy, Post-hypnotic suggestion, and amnesia. Passing each suggestion (showing an observable reaction consistent with the suggestion) is scored 1 point, and the final score is between 0 and 12 points. The reliability of the tool in the present study as measured by Cronbach $\alpha$ was .72. Apart from the objective score, subjective scoring was applied, which involved the participant rating on a Likert-like scale how they subjectively experienced the efficacy of each suggestion (Kirsch, Council, \& Wickless, 1990). Its internal consistency as measured by Cronbach $\alpha$ was .83 .

Barber Suggestibility Scale (BSS; Barber \& Calverley, 1963; Polish adaptation: Siuta, 1982). It is a tool for measuring suggestibility to overt suggestions, similar to those as in the HGSHS:A, but without hypnosis; the instruction merely requires the participants to listen closely, paying attention to suggestions and trying to imagine the suggested phenomena. It consists of eight suggestions: arm lowering, arm levitation, hand lock, thirst hallucination, verbal inhibition, body immobility, posthypnotic response, and selective amnesia. A subjective scale of the perceived efficacy of the suggestions was applied as well (Barber \& Calverley, 1966). Cronbach $\alpha$ for the objective and subjective scores in the present study were .63 and .71 .

Tests of indirect suggestibility:

Sensory Suggestibility Scale (SSS; Gheorghiu, Hodapp, \& Ludwig, 1978; Polish adaptation: Polczyk, 2003). It is a set of devices, which are presented to the participant as "tools for measuring the individual sensitivity of senses to perceive visual, audible, and tactile stimuli". The devices are able to present the announced stimuli, or to fake them. For example, one of the devices is able to present the participant with very weak but visible light. The subject is told to say "Now" as soon as they can see the light getting brighter. In the first trial, which is a dummy one, the light indeed gets brighter. On the second trial it does not, and if the subject announces that he/she can see that it got "brighter", they are given a point on indi- 
rect sensory suggestibility. In sum, there are 24 diagnostic trials, making a possible score from 0 to 24. Its internal consistency was .80 .

Gudjonsson Suggestibility Scale, version 2 (GSS, Gudjonsson, 1997; Polish adaptation: Polczyk, 2000, 2005). It is a procedure designed for measuring interrogative suggestibility, defined as "the extent to which, within a closed social interaction, people come to accept messages communicated during formal questioning, as the result of which their subsequent behavioural response is affected" (Gudjonsson \& Clark, 1986, p. 84). The subject first listens to a short story, and then recalls it. After $50 \mathrm{~min}$ they are asked 20 questions, 15 of which are misleading, e.g. "Did the boy on the bicycle pass a stop sign or traffic lights?" (in fact, this was not mentioned in the story). The number of questions in the case of which the subject accepted the suggestion (in this example, answered "stop sign" or "traffic lights") constitutes the first index of interrogative suggestibility, called Yield and defined as the tendency to include suggestive premises in the answers. After having answered the questions, the subject is told, regardless of their results, that he/she made a lot of mistakes, that it is necessary to ask all the questions again, and this time he/she should try harder. All 20 questions are asked again, and each distinct change of the answer in comparison with the first one is scored as Shift - the tendency to change answers as the result of negative feedback. The general score can be calculated by adding up Yield and Shift. Cronbach $\alpha$ in the present study for Yield, Shift, and the general score were $.76, .66$, and .78 . In the factor analyses, only the general score was applied.

The Emotional Dialogs Test (EDT, Polczyk, 2003) was designed to measure suggestibility connected with mental processes which are perhaps more complex than perception or memory, namely, detecting (nonexistent) emotions as the result of a suggestive instruction telling the participant to estimate the "intensity of emotion". The material to be estimated consists of 19 written dialogs of two persons. The instruction states that a number of these dialogs contain signs of subtle, but visible aggression. The task of the participant is to detect the aggression and rate its intensity on a 5 -point Likert-like scale, from 0 - no aggression, to 5 - extreme aggression. Fifteen of the dialogs are diagnostic and contain no aggression, which was checked with the help of competent judges. In the remaining five dialogs aggression is "objectively" visible, and they serve as dummies. An example of the diagnostic dialog:

A: It was a wonderful stay indeed. It's a pity we have to go.

B: I was my pleasure. I'll be happy to have you as a guest next year.

A: We'll certainly come again, next year or in two years.

B: You're welcome!
The reliability of this measure in the present research, as measured by Cronbach's $\alpha$, was .91 .

\section{PROCEDURE}

Each participant attended two sessions. In one session, testing was individual and included the BSS, the SSS, the EDT, and the GSS (in random order for each participant). The 50-min break required in the GSS was filled with questionnaires which were part of another experiment. The session took about two hours. Half of the participants were tested by the author, the other half by trained students of psychology.

The other session was run in groups from one to six persons and included testing with the HGSHS:A and some other tests which were part of another study. The session took about two hours. The order of both sessions was random among subjects.

\section{RESULTS}

Descriptive statistics and intercorrelations among all measures are presented in Table 1. As can be seen in Table 1, the pattern of correlations among all tests was quite promising, with all tests of direct suggestibility (HGSHS:A and BSS) being positively correlated, and so were two out of three correlations among tests of indirect suggestibility (EDT, SSS and GSS). Moreover, no test of direct suggestibility was significantly related to any of the tests of indirect suggestibility.

In order to verify the hypothesis that there are two factors of suggestibility, one including tests of direct, and the second, of indirect suggestibility, two confirmatory factor analyses (CFA) were performed. Two models were calculated: one including objective scores of tests of direct suggestibility, the second one with subjective ones. In each model, the factor of indirect suggestibility was constituted by the same three tests. Calculations were done by means of the software AMOS 23 (Arbuckle, 2014). The results are presented in Table 2.

The following interpretations of the goodness of fit indices for well-fitted models were assumed:

- the nonsignificant $p$ value for the model (a significant $p$ indicates an incongruence between the hypothesized model and the data);

- $\chi^{2} / d f<5.00$ (Wheaton, Muthen, Alwin, \& Summers, 1977), or 2.00-3.00 (Carmines \& McIver, 1981), or even 2.00 (Byrne, 1989);

- goodness of fit index (GFI) and adjusted GFI(AGFI) > .90 or even .95 (Jöreskog \& Sörbom, 1989);

- normed fit index (NFI) > .90 (Bentler \& Bonett, 1980);

- root mean square error of approximation (RMSEA) $<.05$, or at least < .08 (Browne \& Cudeck, 1993). 
Table 1

Pearson $r$ correlations among all measures

\begin{tabular}{|c|c|c|c|c|c|c|c|c|}
\hline & \multirow[t]{2}{*}{$M$} & \multirow[t]{2}{*}{$S D$} & \multicolumn{6}{|c|}{ Correlations } \\
\hline & & & HGSHS:A & HGSHS:A Sub & BSS & BSS Sub & EDT & SSS \\
\hline HGSHS:A & 5.98 & 2.77 & & & & & & \\
\hline HGSHS:A Sub & 30.88 & 6.98 & $.80^{* *}$ & & & & & \\
\hline BSS & 3.95 & 1.74 & $.55^{* *}$ & $.49^{* *}$ & & & & \\
\hline BSS Sub & 8.53 & 4.07 & $.53^{* *}$ & $.62^{* *}$ & $.60^{* *}$ & & & \\
\hline EDT & 18.17 & 10.20 & .02 & .03 & -.12 & .02 & & \\
\hline SSS & 4.87 & 3.61 & -.01 & .12 & .06 & .08 & $.27^{* *}$ & \\
\hline GSS & 9.79 & 3.66 & .11 & .06 & .10 & .06 & -.02 & $.23^{*}$ \\
\hline
\end{tabular}

Table 2

Results of confirmatory factor analyses

\begin{tabular}{lcc}
\hline & $\begin{array}{c}\text { Direct suggestibility - } \\
\text { objective scores }\end{array}$ & $\begin{array}{c}\text { Direct suggestibility - } \\
\text { subjective scores }\end{array}$ \\
\hline $\mathrm{ML} \chi^{2}(d f)$ & $5.36(4)$ & $0.89(4)$ \\
$p$ & .252 & .926 \\
$\chi^{2} / d f$ & 1.43 & 0.22 \\
Jöreskog GFI & .98 & .99 \\
Jöreskog AGFI & .93 & .99 \\
Bentler-Bonett NFI & .91 & .99 \\
Steiger-Lind RMSEA $(90 \% \mathrm{Cl})$ & $.06(.01-.16)$ & $<.01(<.01-.02)$ \\
Correlation between latent direct and indirect & $-.01(.623)$ & $.05(.877)$ \\
suggestibility $(p)$ & &
\end{tabular}

Note. Due to one of the error terms having negative variation in both models, the solution should be viewed as an approximation only.

As can be seen in Table 2, both models proved to be well fitted to data; the model with subjective scores of direct suggestibility was somewhat better. Thus, the hypothesis stating that there are two factors of suggestibility, direct and indirect, was confirmed. In the light of the nonsignificant correlation between the latent factors of direct and indirect suggestibility, both in models with objective and subjective scores, the hypothesis stating that the two factors are independent was also confirmed. However, because of some abnormalities in the analyses (negative variance of one of the error terms), the solution should be treated with some caution (Figures 1 and 2).

\section{DISCUSSION}

Results of research presented in this article confirm both hypotheses that were stated: there are two factors of suggestibility: direct and indirect. The direct suggest- ibility refers to yielding to overt, obvious and not hidden influence, while indirect suggestibility reflects the tendency to give in to hidden influence, during which the subject is not aware that they are subject to some pressure. In addition, the two factors proved uncorrelated, confirming the second hypothesis stating so.

The results are congruent with the old hypothesis by Sidis (1898), who was the first to distinguish between direct and hidden influence. They also confirm the results presented by Eysenck and Furneaux (1945), and further expand them, as the tests of indirect suggestibility were tapping not only the area of perception, but also memory and higher cognitive processes.

As mentioned in the introduction, the factor of primary suggestibility was usually confirmed in existing research, but the picture with secondary suggestibility was much more complicated. The present study differs from previous research in two aspects: 1) the battery of tests used to measure indirect sug- 


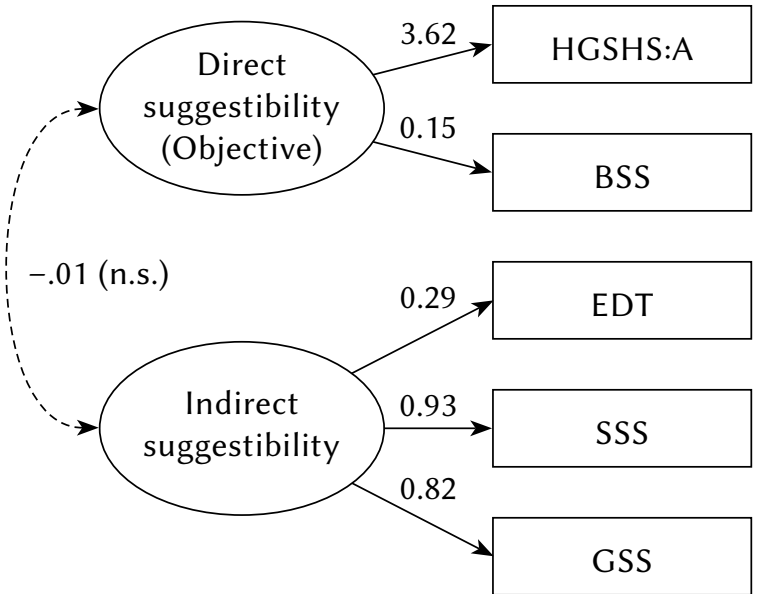

Figure 1. Model with objective testing of direct suggestibility (all paths significant at $p=.05$, apart from the correlation between latent factors. Error terms omitted).

gestibility consisted of standardized tools of known reliability, and 2) this battery was designed to tap not only sensory phenomena (which were the core of secondary suggestibility by Eysenck and Furneaux, 1945), but also other processes: memory and recognizing emotions. Clearly, the primary/secondary distinction does not apply to the present results, and not even to the research strategy itself.

Especially the first of these facts may explain, to some extent, the discrepancies in results between the present study and those described earlier in the literature. As mentioned in the Introduction, up till now, most existing tools for measuring indirect suggestibility have been very simple ones, usually only allowing for a dichotomous classification: "suggestible" (that is, yielding to a given suggestion), or "resistant". In contrast, most existing tests of direct suggestibility have the form of a psychometric tool constructed in accordance with the classical theory of testing, with wellknown reliability, and, most importantly, allowing for measuring on a numerical scale, with a graduation from zero (not suggestible at all) to a given maximum. Scoring on a dichotomous scale must inevitably be less reliable than on a tool containing multiple items and allowing for a continuous measure. This may explain why in most research it was easier to prove the existence of direct than indirect suggestibility.

Apart from the very simple diagnosis, the second serious problem with most existing tools measuring indirect suggestibility is that they are not standardized procedures. Gheorghiu, Polczyk, and Kappeller (2003, p. 221) listed five obvious variations in performing the classical Heat Illusion Test (which largely apply to other classical tests of suggestibility as well): - the duration of the trial - from seconds to a minute (if reported at all);

- the faked purpose of the test communicated to subjects: e.g. "determination of the lower thresh-

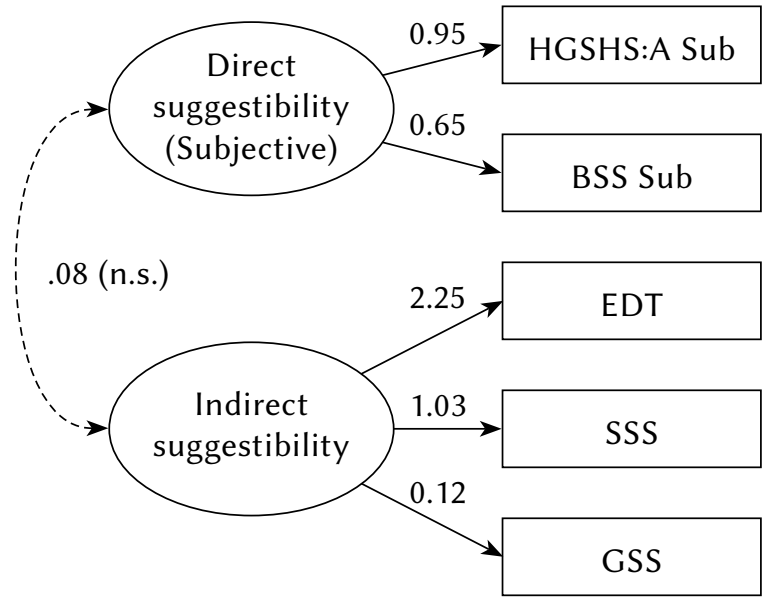

Figure 2. Model with subjective testing of direct suggestibility (all paths significant at $p=.05$, apart from the correlation between latent factors. Error terms omitted).

old for temperature" (Scott, 1910), "heat discrimination and judgment" (Abraham, 1962), "a study of the effects of relaxation" (Hammer et al., 1963) (sometimes not reported);

- the area of the skin that was used for the stimulation (finger, forearm, forehead or others);

- supporting influencing factors, e.g. applying objective heat stimuli before, after or between diagnostic trials;

- the devices used as a faked source of warmth, e.g. wire or rod getting warm, an air blower, etc.

In the present study, tests for measuring indirect suggestibility were standardized, but judging from the matrix of correlations between all the measures used in the present research, it still seems obvious that the correlations among tests of indirect suggestibility were lower (and nonsignificant in one case) than those among tests of direct suggestibility. To some extent this may be understandable, because both tests constituting the direct factor were actually very similar. No effort was undertaken to broaden the battery in the case of direct suggestibility, as the existence of this factor was, as already stated, well established. It was indirect suggestibility which actually was the most important in this study. Nevertheless, the weak correlations between indirect tests suggest that the individual trait relating to susceptibility to hidden influence may be unstable and certainly requires further research. It is still possible that yielding to hidden influence is dependent more on situational factors than a stable individual trait.

\section{LIMITATIONS AND FUTURE DIRECTIONS}

In the present study, the battery of tests was actually quite small as compared to other research of this 
kind, i.e. two measures of direct and three of indirect suggestibility were included, while Eysenck and Furneaux (1945) used 12 of them, six called direct, and six indirect. In the present study, the small number of measures was simply the result of using tests which were much more elaborate than the classical ones and simply required more time to administer (and group testing was impossible in the case of most of them). Research of this kind is unfortunately extremely time-consuming (in the present experiment, both sessions took four hours in sum) and requires some elaborate technical equipment (to my knowledge, at the moment of performing the research presented in this article, the Sensory Suggestibility Scale only existed in two copies). To properly measure both direct and indirect suggestibility, no easy self-description methods are available or even possible (how could one adequately estimate one's one susceptibility to hidden influence?). Better tests come at the price of impossibility to explore a large number of areas towards which the suggestive influence may be directed. This is also related to the second limitation of the present study, namely, the relatively small sample size $(N=118)$. Structural equation modeling usually requires much more observations. This could be the main reason for some technical problems in the analysis, such as negative variances.

Another problem in the present study is the fact that tools for measuring indirect suggestibility are based on different theoretical foundations. On the other hand, however, they share a basic characteristic: they are related to hidden influence. Whether the results on them do correlate or load to a unitary factor is a question which can only be answered by empirical research.

Given the small number of tools/kinds of suggestibility involved in the present research, its results must be treated as preliminary. The fundamental question, whether the stable individual trait "suggestibility" exists at all (Eysenck, 1991) and what, if any, its factorial structure is, needs further research. In order to further expand our understanding of the trait suggestibility, the repository of available tools has to be increased substantially. Technically, the trait "suggestibility" can only be confirmed when tools for measuring it exhibit acceptable test-retest correlation, and results of factor analyses converge in coherent conclusions. Research of this kind seems to be one of the most important future directions in the area of suggestion and suggestibility.

\section{SUMMARY AND CONCLUSIONS}

To my knowledge, this is the first research on the structure of suggestibility performed with contemporary tools which were all constructed in accordance with the classical theory of testing, and were standardized and validated according to standards accepted nowadays. This is important, because they allowed for a quantitative numerical measurement, in the case of which discovering relationships is much easier than with simple tests only allowing for a dichotomous classification: suggestible or nonsuggestible. It is also important that tools used in the present research tap some phenomena that are of greater importance for applied psychology, such as interrogative suggestibility. Distortions of eyewitness memory may have more serious consequences than, say, mistakes consisting in feeling nonexistent warmth.

Confirming the existence of two kinds of suggestibility, the susceptibility to overt direct and hidden indirect influence, relatively independent one from another, also opens new perspectives in the area of looking for personality traits related to yielding to suggestive influence.

\section{REFERENCES}

Abraham, H. H. L. (1962). The suggestible personality: A psychological investigation of susceptibility to persuasion. Acta Psychologica, 20, 167-184.

Arbuckle, J. L. (2014). Amos (Version 23) [Computer Program]. Chicago: SPSS. http://dx.doi. org/10.1016/0001-6918(62)90016-1

Baker, S. L., \& Kirsch, I. (1993). Hypnotic and placebo analgesia: Order effects and the placebo label. Contemporary Hypnosis, 10, 117-126.

Barber, T. X., \& Calverley, D. S. (1963). 'Hypnotic-like' suggestibility in children and adults. Journal of Abnormal and Social Psychology, 66, 589-597.

Bentler, P. M., \& Bonett, D. G. (1980). Significance tests and goodness of fit in the analysis of covariance structures. Psychological Bulletin, 88, 588606.

Benton, A. L., \& Bandura, A. (1953). "Primary" and "secondary" suggestibility. Journal of Abnormal and Social Psychology, 48, 336-340.

Binet, A. (1900). La suggestibilité [The suggestibility]. Paris: Schleicher Frères.

Braffman, W., \& Kirsch, I. (1999). Imaginative suggestibility and hypnotizability: An empirical analysis. Journal of Personality and Social Psychology, 77, 578-587.

Browne, M. W., \& Cudeck, R. (1993). Alternative ways of assessing model fit. In K. A. Bollen \& J. S. Long (eds.), Testing structural equation models (pp. 136-162). Newbury Park, California: Sage.

Byrne, B. M. (1989). A primer of LISREL: Basic applications and programming for confirmatory factor analytic models. New York: Springer-Verlag.

Carmines, E. G., \& Mclver, J. P. (1981). Analyzing models with unobserved variables. In G. W. Bohrnstedt \& E. F. Borgatta (eds.), Social mea- 
surement: Current issues (pp. 55-115). Beverly Hills: Sage.

Darragh, M., Chang, J. W.-H., Booth, R. J., \& Consedine, N. S. (2015). The placebo effect in inflammatory skin reactions: The influence of verbal suggestion on itch and weal size. Journal of Psychosomatic Research, 78, 489-494.

Darragh, M., Chang, J. W.-H., Booth, R. J., \& Consedine, N. S. (2015). The placebo effect in inflammatory skin reactions: The influence of verbal suggestion on itch and weal size. Journal of Psychosomatic Research, 78, 489-494.

Duke, J. D. (1964). Intercorrelational status of suggestibility tests and hypnotizability. Psychological Record, 14, 71-80.

Evans, F. J. (1967). Suggestibility in the normal waking state. Psychological Bulletin, 67, 114-129.

Evans, F. J. (1989). Die Unabhängigkeit von Suggestibilität, Placeboreaktion und Hypnotisierbarkeit [The independence of suggestibility, placebo response, and hypnotizability] (Trans S. Kossak and H.-C. Kossak). Experimentelle Und Klinische Hypnose, 5, 1-17.

Eysenck, H. J. (1947). Dimensions of personality. London, Routledge \& Kegan Paul.

Eysenck, H. J. (1991). Is suggestibility? In J. F. Schumaker (ed.), Human suggestibility. Advances in theory, research, and application (pp. 76-90). New York: Routledge.

Eysenck, H. J., \& Furneaux, A. D. (1945). Primary and secondary suggestibility: An experimental and statistical study. Journal of Experimental Psychology, 35, 485-503.

Eysenck, H. J., Arnold, W. J., \& Meili, R. (1975). Encyclopedia of psychology (Vol. 2). Bungay, Suffolk: Fontana.

Freud, Z. (1920/1975). Psychologia zbiorowości i analiza ego [Group psychology and the analysis of the Ego]. In Z. Freud, Poza zasada przyjemności [Beyond the pleasure principle]. Warszawa: PWN.

Gheorghiu, V. A. (1971). Relations between the direct and indirect forms of the Body Sway Test. Journal of Clinical and Experimental Hypnosis, 19, 134-139.

Gheorghiu, V. A. (1989). The development of research on suggestibility: Critical considerations. In V. A. Gheorghiu, P. Netter, H. J. Eysenck, \& R. Rosenthal (eds.), Suggestion and suggestibility. Theory and research (pp. 3-56). Berlin: Springer Verlag.

Gheorghiu, V. A., Hodapp, V., \& Ludwig, C. M. (1975). Attempt to construct a scale for the measurement of the effect of suggestions on perception. Educational and Psychological Measurement, 35, 341-352.

Gheorghiu, V. A., Meiu, G. H., Onofrei, A. I., \& Timofte, G. (1966). Experimental investigation on suggestibility: On the effects of direct and indirect suggestions. Revue Roumaine des Sciences Sociales, 10, 163-174.
Gheorghiu, V. A., Polczyk, R., \& Kappeller, C. (2003). The Warmth Suggestibility Scale-A procedure for measuring the influence of suggestion on warmth sensations. Personality and Individual Differences, 34, 219-231.

Green, J. P., Barabasz, A. F., Barrett, D., \& Montgomery, G. H. (2005). Forging Ahead: The 2003 APA Division 30 Definition of Hypnosis. International Journal of Clinical and Experimental Hypnosis, 53, 259-264.

Gudjonsson, G. H. (1997). The Gudjonsson Suggestibility Scales. Manual. Hove, UK: Psychology Press.

Gudjonsson, G. H., \& Clark, N. (1986). Suggestibility in police interrogation: A social psychological model. Social Behaviour, 1, 83-104.

Gwynn, M. I., \& Spanos, N. P. (1996). Hypnotic responsiveness, nonhypnotic suggestibility, and responsiveness to social influence. In R. G. Kunzendorf, N. P. Spanos, \& B. Wallace (eds.), Hypnosis and imagination (pp. 147-175). Amityville, NY, US: Baywood Publishing Co.

Hammer, A. G., Evans, F. J., \& Bartlett, M. (1963). Factors in hypnosis and suggestion. Journal of Abnormal and Social Psychology, 67, 15-23.

Hajek, P., \& Kratochvil, S. (1973). Social influencibility and hypnotic susceptibility. Československá Psychologie, 17, 368-374.

Hajek, P., \& Spacek, J. (1987). Territory, hypnotic susceptibility and social influence: A pilot study. British Journal of Experimental \& Clinical Hypnosis, 4, 115-117.

James, W. (1896). The principles of psychology ( $2^{\text {nd }}$ ed.). New York: Holt.

Jöreskog, K. G., \& Sörbom, D. (1989). LISREL 7. A guide to the program and applications ( $2^{\text {nd }}$ ed.). Chicago: SPSS Inc.

Kirsch, I. (1997). Specifying nonspecifics: Psychological mechanisms of placebo effects. In A. Harrington (ed.), The placebo effect: An interdisciplinary exploration (pp. 166-186). Cambridge, MA: Harvard University Press.

Kirsch, I., Council, J. R., \& Wickless, C. (1990). Subjective scoring for the Harvard Group Scale of Hypnotic Susceptibility, Form A. The International Journal of Clinical and Experimental Hypnosis, 38, 112-124.

Linton, C. P., \& Sheehan, P. W. (1994). The relationship between interrogative suggestibility and susceptibility to hypnosis. Australian Journal of Clinical \& Experimental Hypnosis, 22, 53-64.

Loftus, E. F., Miller, D. G., \& Burns, H. J. (1978). Semantic integration of verbal information into a visual memory. Journal of Experimental Psychology: Human Learning and Memory, 4, 19-31.

Loftus, E. F., \& Palmer, J. C. (1974). Reconstruction of automobile destruction: An example of the interaction between language and memory. In S. Fein \& S. Spencer (eds.), Readings in social psychology: 
The art and science of research (pp. 143-147). Boston, MA, US: Houghton, Mifflin and Company.

Lynn, S. J., Laurence, J.-R., \& Kirsch, I. (2015). Hypnosis, suggestion, and suggestibility: An integrative model. American Journal of Clinical Hypnosis, 57, 314-329.

McDougall, W. (1908). Introduction to social psychology. London: Methuen.

McGlashen, T. H., Evans, F. J., \& Orne, M. T. (1969). The nature of hypnotic analgesia and placebo response to experimental pain. Psychosomatic Medicine, 31, 227-246.

Moore, R. K. (1964). Susceptibility to hypnosis and susceptibility to social influence. The Journal of Abnormal and Social Psychology, 68, 282-294.

Netter, P., Gheorghiu, V. A., Kruse, P., \& Hübner, M. (1989). Einflußfaktoren der Suggestibilität [Determinants of suggestibility]. Bericht Nr. 216/5-2. Gießen: Justus-Liebig Universität.

Perez, N. A. (2009). Parsing out everyday suggestibility: A test-retest study. PhD dissertation. University of Tennessee.

Perez, N. A., Brown, S., Tasso, A. F., \& Nash, M. R. (2004). Sensory suggestibility and hypnotic suggestibility: A confirmatory factor analysis. Paper presented at the $55^{\text {th }}$ Annual Conference of the Society for Clinical and Experimental Hypnosis, Santa Fe, NM.

Polczyk, R. (2000). Wpływ społeczny a różnice indywidualne: Skale Sugestybilności Interrogatywnej Gudjonssona [Social influence and individual differences: Gudjonsson Suggestibiltiy Scales]. Kolokwia Psychologiczne nr 8: Wptyw spoteczny: Badania i praktyka. Warszawa: Instytut Psychologii PAN.

Polczyk, R. (2003). Doświadczanie nieistniejącego. Sugestybilność jako cecha indywidualna [Experiencing the nonexistent. Suggestibility as an individual trait]. In K. Krzyżewski (ed.), Doświadczenie indywidualne. Szczególny rodzaj poznania $i$ wyróżniona postać pamięci [Individual experience. A special kind of cognition and memory] (pp. 69-84). Kraków: Wydawnictwo Uniwersytetu Jagiellońskiego.

Polczyk, R. (2005). Interrogative suggestibility: Cross cultural stability of psychometric and correlational properties of the Gudjonsson Suggestibility Scales. Personality and Individual Differences, 38, 177-186.

Polczyk, R., \& Pasek, T. (2006). Types of suggestibility: Relationships Among Compliance, Indirect, and Direct Suggestibility. International Journal of Clinical and Experimental Hypnosis, 54, 392-415.

Register, P. A., \& Kihlstrom, J. F. (1988). Hypnosis and interrogative suggestibility. Personality and Individual Differences, 9, 549-558.

Scott, W. R. (1910). Personal differences in suggestibility. Psychological Review, 17, 147-154.
Shor, R. E., \& Orne, E. C. (1962). Harvard Hypnotic Susceptibility Scale: Form A. Palo Alto, CA: Consulting Psychologists Press.

Sidis, B. (1898). The psychology of suggestion. New York: Appleton.

Siuta, J. (1978). Polska adaptacja Harwardzkiej Grupowej Skali Podatności Hipnotycznej R.E. Shora i E.C. Orne. Maszynopis niepublikowany [Polish adaptation of the Harvard Group Scale of Hypnotic Susceptibility by R.E. Shore and E.C. Orne. Unpublished manuscript].

Siuta, J. (1982). Badania porównawcze nad Skalą Sugestywności Barbera [Comparative research on Barber Suggestibility Scale]. Zeszyty Naukowe UJ, Prace Pedagogiczno-Psychologiczne, 34, 93-112.

Spanos, N. P., Perlini, A. H., \& Robertson, L. A. (1989). Hypnosis, suggestion, and placebo in the reduction of experimental pain. Journal of Abnormal Psychology, 98, 285-293.

Spanos, N. P., Stenstrom, R. J., \& Johnston, J. C. (1988). Hypnosis, placebo, and suggestion in the treatment of warts. Psychosomatic Medicine, 50, 245-260.

Stukat, K. G. (1958). Suggestibility: A factorial and experimental analysis. Stockholm: Almqvist and Wiksell.

Van Dyck, R., \& Hoogduin, K. (1990). Hypnosis: placebo or nonplacebo? Ameican Journal of Psychotherapy, 44, 396-404.

Wheaton, B., Muthen, B., Alwin, D. F., \& Summers, G. F. (1977). Assessing reliability and stability in panel models. In D. R. Haise (ed.), Sociological methodology (pp. 84-136). San Francisco: JossseyBass.

Woody, E. Z., Drugovic, M., \& Oakman, J. M. (1997). A reexamination of the role of nonhypnotic suggestibility in hypnotic responding. Journal of Personality and Social Psychology, 72, 399-407.

Wundt, W. M. (1892). Hypnotismus und Suggestion [Hypnosis and suggestion]. Lepizig: Engelmann. 